\title{
SURFACE TEMPERATURE MODEL - ANALYSIS OF EARTH`S CRUST RESPONSE TO CHANGES IN SURFACE TEMPERATURE
}

\author{
I. Wandrol ${ }^{*}$, K. Frydrýšek ${ }^{* *}$, A. Hofer ${ }^{* * *}$
}

\begin{abstract}
The article has focused on issues from the fields of geophysics and geomechanics, using methods, approaches, skills, and experiences from applied mechanics. Its core topic is the investigation of the influence of exogenous factors on phenomena occurring within the Earth's crust. Based on that, the model was created to explore an exogenous influence - cyclic temperature variation (daily and annual). The article shows statistical calculations for the creation of stochastic models for the process of strain and stress on the surface of the Earth's crust. The outputs of this model are in accordance with measurements of temperatures under the Earth's surface, so the results can be considered relevant. The model showed that changes in stress due to cyclic changes in surface temperatures could reach values of up to $50 \mathrm{MPa}$.
\end{abstract}

Keywords: Earth's crust, plane stress, displacements, elastic foundation, FEM, stochastic evaluation.

\section{Introduction}

The article shows a partial result of the work on the geomechanical model of the Earth's crust. The idea of the model is based on the assumption that cyclical changes in temperature on the Earth's surface cause changes of the stress tensor in the Earth's crust. The stress then spreads across the continental plate in the form of a thermoelastic wave. The first who used the term "thermoelastic wave" was Berger (1975). He deduced relationships between displacement and deformation in depth and periodic changes of surface temperature. Some part of the thermoelastic effect has a significance only on the surface another part penetrates deeper into the massif. As models show, this happens even if the rock is covered by a thin layer of loose material. Results are supported by measurements in the field, e.g. Ben-Zion (1986).

The previous findings have been summed up in the dissertation thesis by Wandrol (2017). To study the effect of the exogenous factor, numerical and stochastic models were designed and processed. The thesis also presents an original and practical solution of the influence of atmospheric phenomena (i.e. atmospheric pressure) on the geomechanics of the Earth, see also Wandrol (2016). Next analysis of meteorological parameters (air temperature, air density, atmospheric pressure changes and synoptic situations) and their influence an Earth's crust response is presented in paper Holub et al. (2013).

This article describes the modeling process and the basic characteristics of one of them, i.e. a model that shows the influence of the daily and annual cyclical changes in temperature on the surface of the Earth's crust on the displacement, temperature and tension in the volume of the Earth's crust. This is a 2D model (plane stress problem) on parts of the homogeneous and isotropic Earth's crust created in software MSC.MARC/MENTAT (Finite Element Method - FEM). The results are processed values and trends of the temperature and stress-deformation field in the whole volume of the Earth's crust. The approach

\footnotetext{
RNDr. Ivo Wandrol, Ph.D.: The Institute of Physics, Faculty of Philosophy and Science, Silesian University in Opava, Bezručovo náměstí 1150/13; 746 01, Opava; CZ, ivo.wandrol@slu.cz

** Assoc. Prof. M.Sc. Karel Frydrýšek, Ph.D., ING-PAED IGIP: Department of Applied Mechanics, Faculty of Mechanical Engineering, VŠB-Technical University of Ostrava, 17. listopadu 15/2172; 708 00, Ostrava; CZ, karel.frydrysek@vsb.cz

*** Mgr. Adam Hofer: The Institute of Physics, Faculty of Philosophy and Science, Silesian University in Opava, Bezručovo náměstí 1150/13; 746 01, Opava; CZ; 746 01, Opava; CZ, adam.hofer@fpf.slu.cz
} 
chosen is entirely new, and the benefit is to quantify changes in temperature, stress and displacements within the Earth's crust as a function of cyclic changes in surface temperature.

\section{The "surface temperature model"}

On the Department of Applied Mechanics (FME VŠB - Technical University of Ostrava) a model simulated the Earth's crust was created (see Fig. 1). The model contains a total of 10116 nodes and 8973 finite elements. Node 1 is located on the surface of the earth's crust exactly at the boundary of the sections no. 1 and 2 indicated in Fig. 1 (i.e. on the material interface between "material1" and "material2"). Each node is defined by its position angle and the depth below the surface (see Fig. 1).

The computation was performed for a period of two years (720 days), when the initial time $\mathrm{t}_{0}=0 \mathrm{~s}$ corresponds to 1st February of the first year and the end time $t_{\max }=63154340 \mathrm{~s}$ corresponds to 31 January of the second year. This period was divided into 20000 computing steps, which took about 9 hours and 17 minutes of computation time on a standard PC.

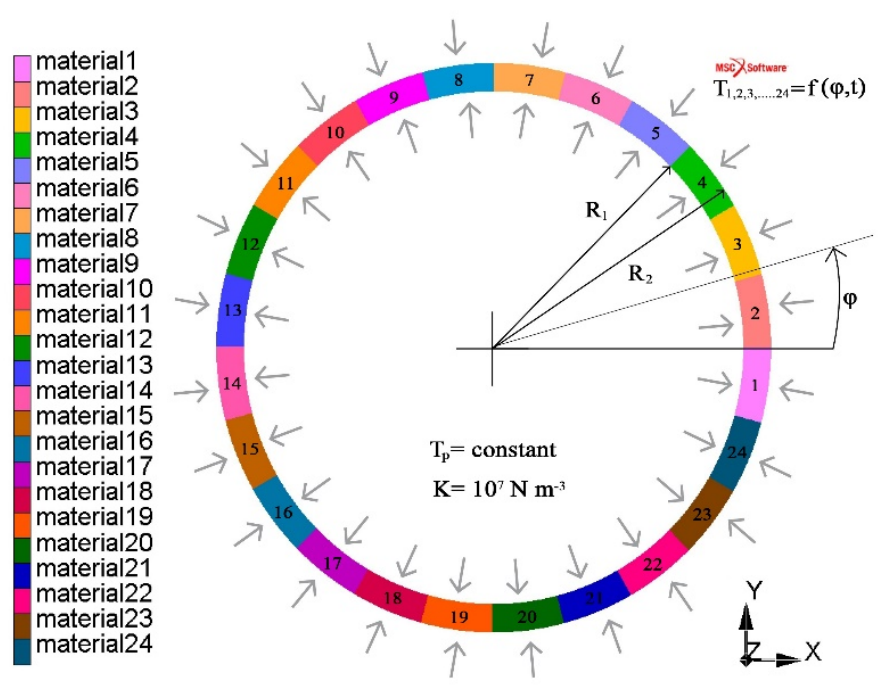

Fig. 1: Surface temperature model (model is not to scale)

The model includes non-homogeneity in the form of 24 sections. Each section corresponds to one type of linear material defined by six material variables (simplified modeling of the effects of nonhomogeneities).

The surface of the planet Earth, i.e. the Earth's crust, is replaced by a thin circular band, i.e. a network of finite elements, with an internal radius of $R_{1}=6348 \mathrm{~km}$ and an outer radius $R_{2}=6378 \mathrm{~km}$, which is the Earth's radius. The thickness of the Earth's crust is approx. $30 \mathrm{~km}$ for this model.

The material properties of the lithospheric plates are generally inhomogeneous. To approximate the real state in the real environment, the model is designed in parts homogeneous and isotropic. In Fig. 1, this represents the variously colored and numbered parts of the annulus. The Earth's crust (360 degrees) is divided into 24 identical sections with the names "material1" to "material24", i.e. the division of fifteen degrees. On the Earth's crust model can be seen as a mixture of 24 materials whose material values are within the range for Young's modulus of elasticity $\mathrm{E} \in<3.0 \times 10^{10} ; 4.5 \times 10^{10}>$ [Pa], Poisson constant

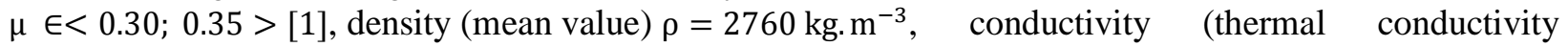
coefficient) $\lambda=3 \mathrm{~W} \cdot \mathrm{m}^{-1} \cdot \mathrm{K}^{-1}$, specific heat capacity $\mathrm{c}=1100 \mathrm{~J} \cdot \mathrm{kg}^{-1} \cdot \mathrm{K}^{-1}$, thermal coefficient of linear expansion $\alpha \in<3.5 \times 10^{-5} ; 4.5 \times 10^{-5}>\left[\mathrm{K}^{-1}\right]$.

For different sections are set in the model different material quantities in accordance with the previous overview. This makes the model a simple with the acceptable variety of materials. The real values of material quantities of materials contained in the Earth's crust can be found in Mareš (1990).

Below the Earth's crust is the upper mantle. The model solves a plane stress problem (acceptable simplification of the spatial tension). The Earth's crust is replaced by a network of finite elements, and the interface between the Earth's crust and the Earth's upper mantle is replaced by Winkler elastic foundation, 
where the foundation modulus is approx. $\mathrm{K}=10^{7} \mathrm{~N} \cdot \mathrm{m}^{-3}$. The Earth's plate is therefore resiliently mounted on the mantle.

For the model, initial and boundary conditions were determined to simulate temperature at the top and bottom edges of the earth's crust. The model assumes that the bottom edge temperature is constant. Beazly (1981) shows a mean value at a depth of $30 \mathrm{~km} \mathrm{~T}_{\mathrm{p}}=375^{\circ} \mathrm{C}=648.15 \mathrm{~K}$. Another initial condition was the mean surface temperature of the Earth's crust $\bar{T}_{\text {outer }}=13.85^{\circ} \mathrm{C}=287 \mathrm{~K}$. Based on the temperatures defined above on the inner and outer surface of the Earth's crust, an initial condition for preheating the model was created in accordance with the heat conduction equation. The whole theoretical derivation can be found in Wandrol (2017).

The boundary condition of the Earth's crust temperature model simulates cyclical temperature changes based on the daily rotation cycle and an annual Earth's orbital period. On a basic diagram in Fig. 1 are shown as a function of $T_{1}, T_{2}, \ldots, T_{24}=f(\varphi, t) / K /$ for each section. A total of 24 temperature time ranges were added to the model. Temperature ranges were created from real-time surface temperature data. The data was downloaded from the ALA monitoring system web site (System ALA 2017). The data of the Blatnička station, which is located in South Moravia near Hodonín, was used for the calculation.

The initial conditions of the model are only an approximation of the complex state of reality. This is a completely new method of modeling the Earth's crust. The authors of the paper didn't find a similar approach in the literature and this is why the originality of our contribution. Therefore, one of the goals of the geomechanical model was to verify the admissibility of this method.

\section{Analysis of displacement and stress on the surface of the Earth's crust}

For analysis, based on selected criteria we calculated days when an extreme value of some variables occurred in node 1 of the model: Temperature, equivalent stress according to von Mises ("HMH tension") or absolute displacement values.

The calculation showed that the difference of the maximum and minimum HMH stress on the surface in one day reaches values above $24 \mathrm{MPa}$. It can be assumed that the very high variability of the stress caused by changing the daily and annual cycle temperatures on the Earth's crust surface can significantly contribute to the formation of irreversible deformations within the Earth's crust. These deformations may be insignificant from the point of view of the volume of the earth's crust, but their constant repetition may lead to significant seismic and volcanic phenomena.

Surface node analysis was performed for $\mathrm{HMH}$ stresses and for displacement of nodes in radial and tangential directions. For all selected nodes on the surface of the Earth's crust (i.e. 48 nodes), a stochastic model was created using SW Anthill, and animation was developed to show the behavior of the Earth's crust over the two-year calculation interval. Figure 2 shows displacement vectors in one day of model calculation (day 331). Attention was focused on comparing both types of displacements in the individual nodes on the surface. Table 1 shows the statistical characteristics of radial and tangential displacements.

Tab. 1: Statistical characteristics of radial and tangential displacement of nodes on the surface.

\begin{tabular}{|c|c|c|c|c|}
\cline { 2 - 5 } \multicolumn{1}{c|}{} & Minimum /m/ & Mean $/ \mathbf{m} /$ & Median $/ \mathbf{m} /$ & Maximum $/ \mathbf{m} /$ \\
\hline Radial & -3.991671 & -0.613224 & -0.565907 & 2.816905 \\
\hline Tangential & -29.331777 & 0.063933 & 0.059297 & 40.070023 \\
\hline
\end{tabular}

The average value for all nodes on the surface of the Earth's crust is negative - that is, for most nodes on the surface, the surface is pressed towards the center of the Earth. The model showed that tangent displacements in absolute value are significantly larger than radial displacements.

In SW Anthill environment (application of the Monte Carlo method) histograms of HMH stress distribution were developed for each surface node. In Fig. 2, histograms of HMH stress are found on all surface nodes together.

HMH stress histograms for each node has a similar character. Numerical quantification values differ significantly only for node 1 values. In this case, all three (median, minimum and maximum) characteristics are higher than the other nodes. The maximum HMH value in this node is $52.09 \mathrm{MPa}$ and the median is $15.1 \mathrm{MPa}$. 


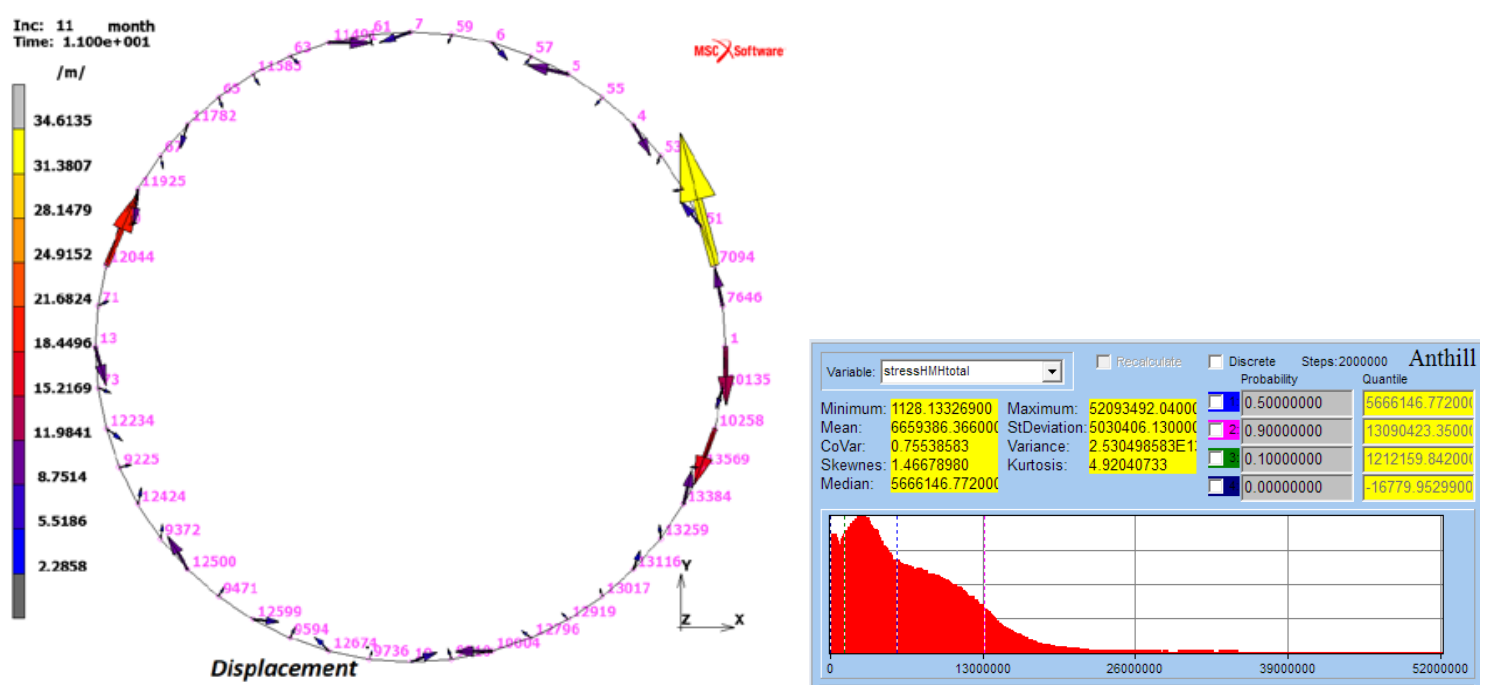

Fig. 2: Displacement vectors in day 331 (Earth's crust upper surface) \& histogram for equivalent von Mises stress across the Earth's crust thickness $\sigma_{H M H} \in<0.001 ; 52.102>M P a$

\section{Conclusions}

Data analysis of surface temperature model for nodes at Earth`s crust surface profile and stress shows:

- Radial movement $u_{\mathrm{r}}$ oscillates more around zero, i.e. $\mathrm{u}_{\mathrm{r}}=-0.57_{-3.42}^{+3.39} \mathrm{~m}$. Tangential movement displays a considerably greater variance, i.e. $\mathrm{u}_{\varphi}=0.06_{-29.39}^{+40.01} \mathrm{~m}$.

- However, there are also nodes which deviate considerably in tangential direction towards one side. In general, it can be stated that the tangential displacement displays a significantly greater dispersion than the radial displacement (see table 1 ).

- The values differ significantly at different points on the surface, however, in the view of the structure of the model, this may be due primarily to different materials in individual sections interacting at section boundaries.

- The distribution of HMH stress is largely similar at all nodes on the surface.

- The influence of cyclical changes in surface temperatures is one proof of the possible initiation of fractures, movements, subductions and other seismic phenomena, as changes in stress at the surface $\sigma_{\text {нмн }} \in<0.001 ; 52.102>\mathrm{MPa}$ are so great that they may reach limit values.

- The non-homogenous environment in the model has a dominant influence on this fact.

\section{Acknowledgement}

The authors gratefully acknowledge the funding from the Czech projects SP2018/63.

\section{References}

BEAZLEY, M. (1981) The Anatomy of the Earth. Prague: Albatros, 1981. 121 p. (in Czech)

BEN-ZION, Y. a P. Leary. (1986) Thermoelastic strain in a half-space covered by unconsolidated material. Bulletin of the Seismological Society of America. 1986, 76(5), p. 1447-1460. ISSN 0037-1106.

BERGER, J. (1975) A note on thermoelastic strains and tilts. Journal of Geophysical Research. 1975, 80(2), p. 274277. DOI: 10.1029/JB080i002p00274. ISSN 2156-2202.

HOLUB, K., P. Kalenda, and J. Rušajová, (2013): Mutual coupling between meteorological parameters and secondary microseisms. Terr. Atmos. Ocean. Sci., 24, 933-949, doi: 10.3319/TAO.2013.07.04.01(T)

MAREŠ, S., Gruntorád, J., Hrách, S., Karous, M., Marek, F., Matolín, M., Skopec. J. (1990) Introduction to Applied Geophysics: University textbook. 2nd edition. Prague: SNTL, 1990. 677 p. (in Czech).

System ALA [online]. [2017] [cit. 2017-06-16]. Web page, results of surface temperature measurement by ALA. Available from: http://teranos.ala1.com/

WANDROL, I., Frydrýšek, K. (2016) Simple Probabilistic Model for the Influence of the Atmosphere on the Earth's Crust. In: Modelling, Simulation and Identification / 841: Intelligent Systems and Control [online]. Calgary, AB, Canada: ACTAPRESS, 2016, p. - [cit. 2017-06-16]. DOI: 10.2316/P.2016.840-046. ISBN 978-088986-983-7.

WANDROL, I. (2017) Modelling of mechanical behavior of the Earth's crust. Ostrava, 2017, 160 p. Dissertation thesis. VŠB - Technical University of Ostrava, Faculty of Mechanical Engineering. Advisor Karel Frydrýšek. 